\title{
Rancang Bangun Sensor Node pada Wireless Sensor Network Menggunakan Deret Sensor Gas dan Jaringan Syaraf Tiruan untuk Mendeteksi Kebakaran Hutan
}

\author{
Luthfan Aufar Akbar, Muhammad Rivai, dan Fajar Budiman \\ Jurusan Teknik Elektro, Fakultas Teknologi Industri, Institut Teknologi Sepuluh Nopember (ITS) \\ Kampus ITS Sukolilo, Surabaya 60111 \\ e-mail: muhammad_rivai@ee.its.ac.id, luthfanaufar.akbar@gmail.com
}

\begin{abstract}
Abstrak - Kebakaran hutan merupakan bencana yang melanda di Indonesia beberapa bulan terakhir ini. Belum ada solusi nyata baik dari masyarakat dan pemerintah untuk mencegah kebakaran hutan ini. Dalam penelitian ini dilakukan rancang bangun sensor node pada Wireless Sensor Network (WSN) untuk membuat alat deteksi asap kebakaran hutan. Sumber energi listrik akan diperoleh dari panel surya. Alat ini dilengkapi dengan deret sensor gas, yaitu sensor MQ-7, sensor TGS2600, dan sensor MQ-2. Tujuan dari deret sensor gas ini adalah mendeteksi karakteristik tegangan pada ketiga asap yang diujikan, yaitu asap kebakaran hutan, asap rokok, dan asap kendaraan bermotor. Untuk mendukung deret sensor gas di atas, digunakan mikrokontroler STM32f4 sebagai komponen utama. Setelah bisa mendeteksi karakteristik tegangan ketiga asap di atas, proses berlanjut ke sistem Jaringan Syaraf Tiruan agar bisa membedakan antara asap kebakaran hutan atau bukan. Jaringan Syaraf Tiruan yang digunakan adalah tiga layer dengan satu layer tersembunyi dan fungsi aktivasi pada layer tersembunyi adalah sigmoid serta layer output adalah linear. Dari 7 percobaan sistem Jaringan Syaraf Tiruan yang dilakukan, tidak terdapat error dalam pendeteksian asap kebakaran hutan atau bukan. Waktu untuk pendeteksian alat ini sekitar 15 detik.
\end{abstract}

Kata Kunci-Deret Sensor Gas, Jaringan Syaraf Tiruan, Kebakaran Hutan, Sensor Node

\section{PENDAHULUAN}

I NDONESIA salah satu negara yang mempunyai hutan terluas di dunia. Hutan di Indonesia tersebar dari Pulau Sumatra hingga ke Papua. Tahun 2009 luas tutupan hutan Indonesia adalah 88,17 juta ha atau sekitar 46,33 persen dari luas daratan Indonesia. Sebaran tutupan hutan terluas berada di Pulau Papua dengan persentase sebesar 38,72 persen dari total luas tutupan hutan Indonesia, atau sekitar 34,13 juta ha. Wilayah hutan di Indoensia mempunyai peranan penting sebagai pengahasil oksigen ke seluruh dunia [1].

Permasalahan yang terjadi beberapa bulan terakhir ini adalah kebakaran hutan. Bencana ini sudah setiap tahun terjadi bahkan semakin tahun wilayah yang terbakar semakin luas. Salah satu penyebab dari kebakaran hutan ini adalah dibakar secara sengaja oleh oknum-oknum yang tidak bertanggung jawab untuk dibuat lahan sawit atau membuka lahan baru. Sedangkan kebakaran tak disengaja lebih disebabkan oleh kelalaian karena tidak mematikan api unggun, pembakaran sampah, membuang puntung rokok, dan tindakan kelalaian lainnya.

Kebakaran hutan berdampak besar bagi kehidupan manusia. Sebagian besar dampak tersebut bersifat merugikan. Kebakaran hutan merupakan bencana bagi keanekaragaman hayati. Tak terhitung berapa jumlah spesies tumbuhan dan plasma nutfah yang hilang. Selain itu kebakaran hutan banyak melepaskan emisi karbon dan gas rumah kaca lain ke atmosfer. Asap yang ditimbulkan oleh kebakaran hutan berdampak langsung pada kesehatan, khususnya gangguan saluran pernapasan. Asap mengandung sejumlah gas dan partikel kimia yang menggangu pernapasan seperti seperti sulfur dioksida $\left(\mathrm{SO}_{2}\right)$, karbon monoksida $(\mathrm{CO})$, formaldehid, akrelein, benzen, nitrogen oksida $\left(\mathrm{NO}_{\mathrm{x}}\right)$ dan ozon $\left(\mathrm{O}_{3}\right)$. Material tersebut memicu dampak buruk yang nyata pada manula, bayi dan pengidap penyakit paru. Meskipun tidak dipungkiri dampak tersebut bisa mengenai orang sehat [2].

Berangkat dari permasalahan di atas, dilakukan penelitian untuk membuat sensor node dengan menggunakan deret sensor gas dan jaringan syaraf tiruan untuk mendeteksi kebakaran hutan secara dini. Deret sensor gas terdiri atas 3 sensor, yaitu sensor MQ-7, sensor TGS2600, dan sensor MQ-2. Jaringan syaraf tiruan berfungsi untuk menentukan apakah asap yang terdeteksi adalah asap kebakaran hutan atau bukan melalui karakteristik tegangan setiap asap yang diujikan ke deret sensor gas. Diharapkan dari penelitian ini bisa mendeteksi asap kebakaran hutan dengan cepat serta mengurangi angka kebakaran hutan di Indonesia.

\section{TINJAUAN PUSTAKA}

\section{A. Sensor Figaro TGS2600}

Figaro TGS 2600 adalah transducer utama yang digunakan dalam rangkaian ini, yang merupakan sebuah sensor kimia atau gas sensor. Sensor ini mempunyai nilai resistansi Rs yang akan berubah bila terkena gas dan juga mempunyai sebuah pemanas (heater) yang digunakan untuk membersihkan ruangan sensor dari kontaminasi udara luar [3].

Bahan detektor gas dari sensor adalah metal oksida, khususnya senyawa $\mathrm{SnO}_{2}$. Ketika kristal metal oksida $\left(\mathrm{SnO}_{2}\right)$ dihangatkan pada temperatur tertentu, oksigen akan diserap pada permukaan kristal dan oksigen akan bermuatan negatif. Hal ini disebabkan karena permukaan kristal mendonorkan 
elektron pada oksigen yang terdapat pada lapisan luar, sehingga oksigen akan bermuatan negatif dan muatan positif akan terbentuk pada permukaan luar kristal. Tegangan permukaan yang terbentuk akan menghambat laju aliran elektron [4].

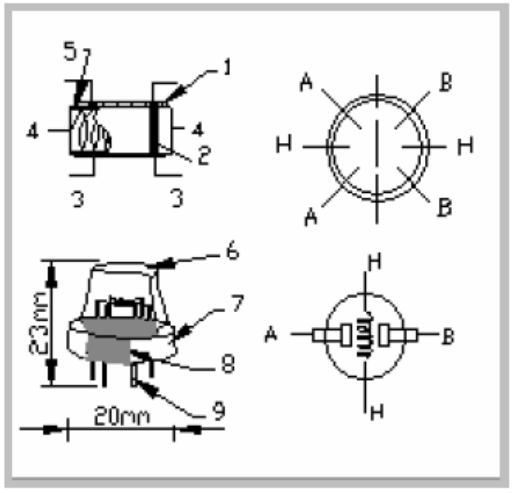

\begin{tabular}{|c|c|c|}
\hline & Parts & Materials \\
\hline 1 & $\begin{array}{c}\text { Gas sensing } \\
\text { layer }\end{array}$ & $\mathrm{SnO}_{2}$ \\
\hline 2 & Electrode & $\mathrm{Au}$ \\
\hline 3 & Electrode line & $\mathrm{Pt}$ \\
\hline 4 & Heater coil & $\mathrm{Ni}-\mathrm{Cr}_{\mathrm{r}}$ alloy \\
\hline 5 & Tubular ceramic & $\mathrm{Al}_{2} \mathrm{O}_{3}$ \\
\hline 6 & $\begin{array}{l}\text { Anti-explosion } \\
\text { network }\end{array}$ & $\begin{array}{l}\text { Stainless steel gauze } \\
\text { (SUS316 100-mesh) }\end{array}$ \\
\hline 7 & Clamp ring & Copper plating Ni \\
\hline 8 & Resin base & Bakelite \\
\hline 9 & Tube Pin & Copper plating $\mathrm{Ni}$ \\
\hline
\end{tabular}

Gambar 1. Struktur Sensor MQ-7 [5]

\section{B. Sensor $M Q-7$}

MQ-7 merupakan sensor gas yang digunakan dalam peralatan untuk mendeteksi gas karbon monoksida (CO) dalam kehidupan sehari-hari, industri, atau mobil. Fitur dari sensor gas MQ7 ini adalah mempunyai sensitivitas yang tinggi terhadap karbon monoksida (CO), stabil, dan berumur panjang. Sensor ini menggunakan catu daya heater: $5 \mathrm{~V}$ DC dan menggunakan catu daya rangkaian: 5V DC, jarak pengukuran: 20 - 2000 ppm untuk ampuh mengukur gas karbon monoksida.

Nilai resistansi MQ-7 adalah perbedaan untuk berbagai jenis dan berbagai gas konsentrasi. Bila menggunakan komponen ini, penyesuaian sensitivitas sangat diperlukan. Disarankan pula untuk mengkalibrasi detektor untuk CO 200ppm di udara dan menggunakan nilai resistansi beban itu (RL) sekitar $10 \mathrm{~K} \Omega$ $(5 \mathrm{~K} \Omega$ sampai $47 \mathrm{~K} \Omega$ ). Ketika secara akurat mengukur, titik alarm yang tepat untuk detektor gas harus ditentukan setelah mempertimbangkan pengaruh suhu dan kelembaban [5].

\section{Sensor $M Q-2$}

Sensor MQ-2 adalah salah satu sensor sensitif terhadap gas. Bahan utama sensor ini adalah $\mathrm{SnO} 2$ dengan konduktifitas rendah pada udara bersih. Jika terdapat kebocoran gas konduktifitas sensor menjadi lebih tinggi, setiap kenaikan konsentrasi gas maka konduktivitas sensor juga naik. MQ-2 sensitif terhadap gas LPG, Propana, Hidrogen, Karbon Monoksida, Metana dan Alkohol.Sensor MQ-2 terdapat 2 masukan tegangan yakni VH dan VC. VH digunakan untuk tegangan pada pemanas (Heater) internal dan Vc merupakan tegangan sumber. Catu daya yang dibutuhkan pada sensor MQ2 adalah $\mathrm{Vc}<24 \mathrm{VDC}$ dan $\mathrm{VH}=5 \mathrm{~V} \pm 0.2 \mathrm{~V}$ Tegangan $\mathrm{AC}$ atau
DC [6].

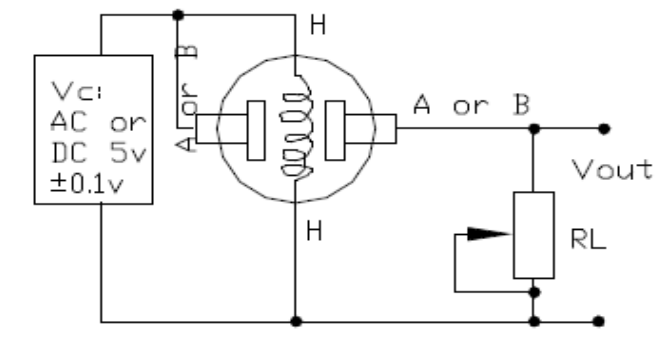

Gambar. 2. Rangkaian Dasar Sensor MQ-2 [6]

Besar nilai dari Resistansi Sensor $(\mathrm{RS})=(\mathrm{Vc} / \mathrm{VRL}-1) \mathrm{x}$ RL. Sensor MQ-2 tersebut terbuat dari bahan peka gas yaitu $\mathrm{SnO}$. Jika sensor tersebut mendeteksi keberadaan gas tersebut di udara dengan tingkat konsentrasi tertentu, maka sensor akan menganggap terdapat asap rokok di udara. Ketika sensor mendeteksi keberadaan gas-gas tersebut, maka resistansi elektrik sensor akan turun. Dengan memanfaatkan prinsip kerja dari sensor MQ-2 ini, kandungan gas tersebut dapat diukur [6].

\section{Mikrokontroler STM32f4-Discovery}

Mikrokontroler STM32F4 discovery adalah mikrokontroler berbasis arsitektur ARM (Advanced Risc Machine) sebuah prosesor 32 bit yang lebih handal dalam hal transfer data dan hemat daya. Chip STM32F429ZIT6U mempunyai banyak fitur yang dapat digunakan, seperti I/O, Timer, ADC, dan DMA. Kecepatan clock-nya bisa mencapai $168 \mathrm{Mhz}$ sehingga memungkinkan untuk mengerjakan perintah program yang cukup panjang dalam waktu yang cukup singkat [8].

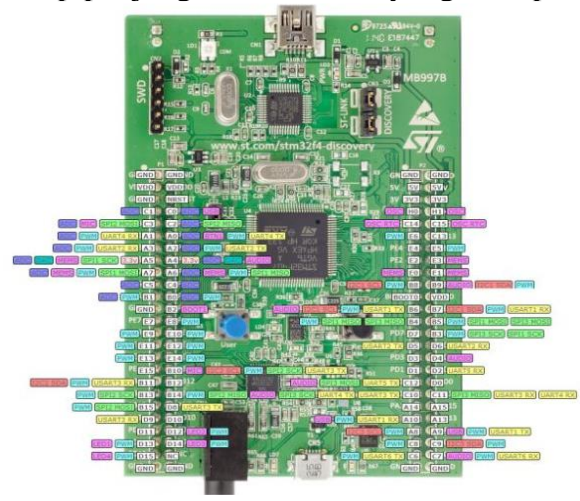

Gambar 3. Mikrokontroler STM32f4-Discovery [8]

\section{E. Jaringan Syaraf Tiruan}

Jaringan syaraf tiruan adalah merupakan pemodelan untuk hubungan antara input dan output pada sejumlah pola data. Jaringan syaraf tiruan merupakan sistem komputasi yang arsitekturnya didekati oleh sel syaraf yang berada dalam otak manusia. Jaringan syaraf tiruan terdiri dari beberapa neuron yang saling terhubung. Pada jaringan syaraf, hubungan antar neuron-neuron dikenal dengan nama bobot. Jaringan dengan banyak lapisan (multilayer net) memiliki 1 atau lebih lapisan yang terletak diantara lapisan input dan lapisan output. Ada lapisan yang berbobot yang terletak antara 2 lapisan yang bersebelahan [7]. 


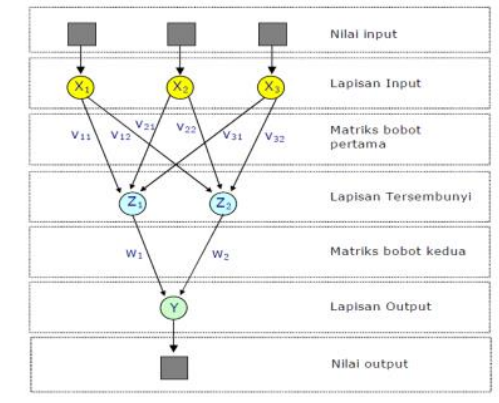

Gambar 4. Jaringan Syaraf Tiruan Multilayer[7]

\section{PERANCANGAN SISTEM}

\section{A. Diagram Blok Sistem}

Secara umum sistem ini terdiri dari perangkat keras dan perangkat lunak. Perangkat keras meliputi perancangan perangkat elektrik, dan perangkat mekanik. Perangkat lunak meliputi program STM32F4 dan jaringan syaraf tiruan menggunakan software keil uvision.

Sistem kerja alat ini adalah ketiga sensor mendeteksi asap yang diujikan. Proses interface yaitu pada LCD 20x4 dengan masing-masing tegangan dari sensor dan peringatan apakah asap hutan atau bukan. Output dari sensor berupa tegangan, tegangan ini adalah data analog yang akan di inputkan ke STM32f4-discovery. Setelah diinputkan pada STM32f4discovery maka data dari ketiga sensor tersebut akan diolah pada sistem jaringan syaraf tiruan. Pada sistem jaringan syaraf tiruan ini akan menentukan jenis asap apa yang terdeteksi. Asap kebakaran hutan atau bukan.

Output dari sistem ini berupa data sesuai dengan asap yang terdeteksi. Jika yang terdeteksi bukan asap hutan maka keluaran STM32f4-discovery berupa angka 0 atau dengan kata lain wireless sensor network tidak aktif karena STM32f4-Discovery tidak mengirim data serial ke WSN. Jika yang terdeteksi adalah asap kebakaran hutan, maka keluaran dari STM32f4-discovery adalah angka 1 atau dengan kata lain wireless sensor network akan aktif karena STM32f4-discovery mengirim data serial tersebut ke WSN.

\section{B. Perancangan Perangkat Keras}

\section{Panel Surya}

Panel surya pada sistem ini berfungsi sebagai power supply, dimana power supply adalah perangkat elektronika yang mensuplai sumber listrik ke perangkat elektronika lainnya.

Tegangan yang dihasilkan oleh panel surya ini maksimal adalah 35 volt dalam keadaan panas matahari diterima secara maksimal. Panel surya ini nanti akan terhubung ke charge controller yang berfungsi untuk menstabilkan tegangan pada nilai 12 volt. Kelebihan dari panas matahari yang diterima akan disimpan pada baterai atau aki, sehingga pada malam hari ketika tidak ada panas matahari sistem diharapkan akan tetap bekerja. Dari charge controller, tegangan akan langsung diterima oleh sistem dan dibagi menjadi 2 bagian, yaitu 12 volt untuk kipas penghisap udara dan 5 volt untuk STM32f4Discovery serta deret sensor gas.

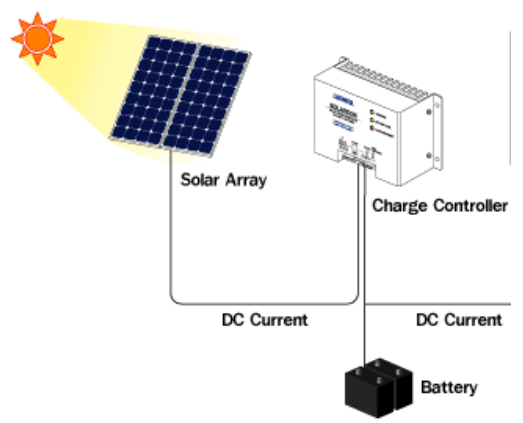

Gambar 5. Diagram Panel Surya

\section{Rangkaian Deret Sensor Gas}

Rangkaian deret sensor gas adalah rangkaian 3 macam sensoruntuk melihat karakteristik masing-masing jenis asap dari tegangan output yang dihasilkan.Perangkat elektrik ini diperlukan untuk mendapatkan tegangan yang stabil dari masing-masing jenis asap yang dideteksi. Ketiga sensor diatas menggunakan rangkaian berupa voltage divider atau rangkaian pembagi tegangan. Rangkaian ini berfungsi mengatur tegangan Vout atau Vrl saat ketiga sensor sedang mendeteksi asap atau tidak. Ketika sensor diaktifkan nilai tegangan ketiga sensor akan naik sesuai dengan jenis asap yang dideteksi, ketika tidak mendeteksi gas kembali tegangan Vout turun secara perlahan.

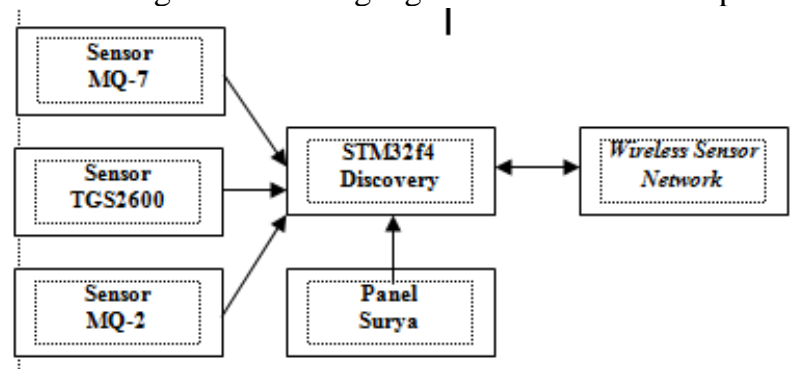

Gambar 6. Diagram Blok Sensor Node

\section{STM32f4-Discovery}

Dalam tugas akhir ini menggunakan STM32f4-discovery. Teganganoutput dari ketiga sensor berupa data analog. Fungsi dari STM32F4 ini untuk mengkonversi data analog menjadi digital dengan memanfaatkan ADC internal dengan resolusi 12 bit dan mengolahnya menjadi input dari jaringan syaraf tiruan. Namun, yang perlu diperhatikan adalah tegangan input maksimal pin ADC dari STM32f4-discovery adalah 3,3 volt sedangkan tegangan output maksimal dari ketiga sensor gas adalah 5 volt. Oleh karena itu, perlu dipasang rangkaian pembagi tegangan dari output ketiga sensor sehingga sebelum masuk STM32f4-discovery tegangan maksimal hanya 3,3 volt dan tidak akan merusak STM32f4-discovery itu sendiri.

4. LCD 20x4

LCD 20x4 berfungsi untuk menampilkan tegangan analog yang dibaca oleh sensor dan menampilkan apakah asap yang terdeteksi asap kebakaran hutan atau bukan. Pada baris pertama digunakan untuk menampilkan tegangan sensor MQ-7, baris kedua menampilkan tegangan sensor TGS2600, baris ketiga menampilkan tegangan sensor MQ-2, dan baris keempat menampilkan status apakah asap kebakaran hutan atau bukan. Suplai tegangan untuk LCD 20x4 sebesar 5 volt yang berasal dari STM32f4-discovery. 
Tabel 1.

Pin LCD 20x4 pada STM32f4-Discovery

\begin{tabular}{cc}
\hline \hline Pin & Port STM32f4 \\
\hline Vss & Gnd \\
Vdd & Vcc \\
Vout & Vcc \\
RS & D10 \\
R/W & Gnd \\
E & D9 \\
DB4 & B15 \\
DB5 & B13 \\
DB6 & B11 \\
DB7 & E15 \\
K & Gnd \\
A & Vcc \\
\hline \hline
\end{tabular}

\section{Perancangan Perangkat Lunak}

1. Pembacaan Nilai ADC dan Menampilkan di LCD

Perangkat lunak STM32 secara umum digunakan untuk mengkonversikan data analog menjadi data digital dengan memanfaatkan ADC internal sebesar 12 bit. Proses ini menggunakan software keil uvision5 dalam proses program data sensor dan jaringan syaraf tiruan. Perangkat lunak STM32F4 menggunakan clock $12 \mathrm{MHz}$, USART transmitter dengan Baud Rate 115200, dan ADC yang digunakan 12 bit. Port yang digunakan adalah PA0, PA1, dan PA5. Setelah tegangan analog dibaca oleh STM32f4-discovery, maka proses selanjutnya adalah mengalikan tegangan digital dengan 3.3 agar tegangan yang dikeluarkan di LCD besarnya sama dengan tegangan pada sensor. Menampilkan hasil pembacaan ADC pada LCD 20x4 bertujuan untuk me-monitoring secara waktu nyata berapa tegangan keluaran masing-masing sensor dan melihat karakteristik tegangan masing-masing sensor terhadap asap tertentu.

2. Proses Jaringan Syaraf Tiruan

Proses dari jaringan syaraf tiruan disini untuk menentukan asap yang terdeteksi apakah asap kebakaran hutan atau bukan. Penentuan asap kebakaran hutan atau dilihat dari karakteristik tegangan output masing-masing sensor terhadap asap yang dideteksi. Setelah terdeteksi berapa tegangan pada masing masing sensor maka akan dilakukan proses training atau latihan secara perhitungan matematis untuk menentukan W (bobot) masing-masing sensor dan B (bias).

Pada sistem Jaringan Syaraf Tiruan ini digunakan tiga layer dengan layer input, layer tersembunyi, dan layer output. Untuk fungsi aktivasi digunakan fungsi aktivasi sigmoid pada layer tersembunyi dan. Fungsi aktivasi hardlim ini cara kerjanya adalah bila nilai output $\mathrm{a}=0$ maka bukan asap kebakaran hutan. Jika nilai output $\mathrm{a}=1$ maka asap kebakaran hutan.

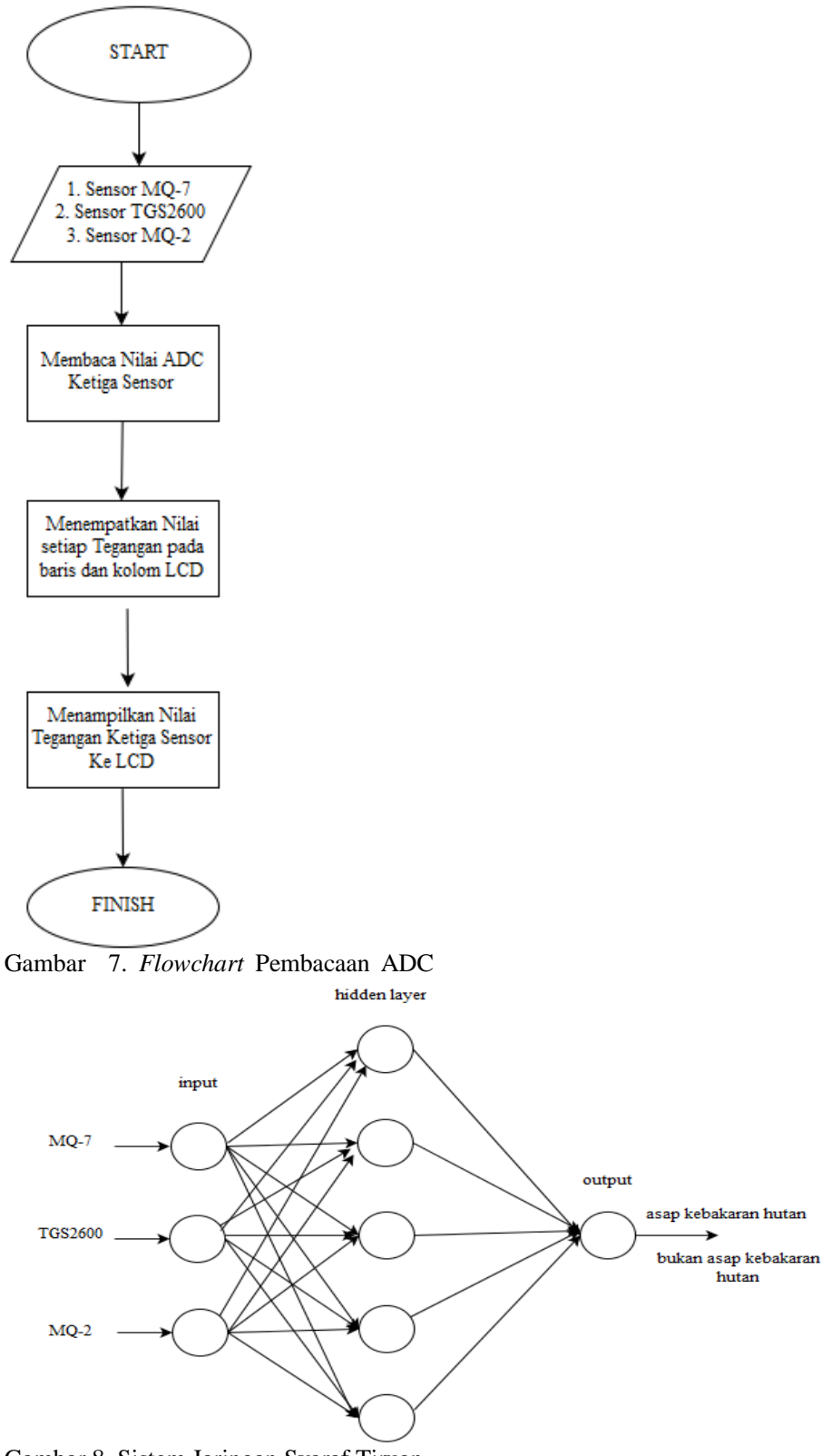

Gambar 8. Sistem Jaringan Syaraf Tiruan

\section{PENGUKURAN DAN ANALISIS DATA}

\section{A. Pengujian Perangkat Keras}

\section{Pengujian Supply Sistem}

Rangkaian power supply merupakan rangkaian terpenting yang digunakan sembagai sumber daya dari seluruh sub rangkaian elektrik. Output dari rangkaian ini adalah tegangan DC $12 \mathrm{~V}$ dan $5 \mathrm{~V}$.

Untuk mendapatkan tegangan 5 volt pada rangkaian power supply menggunakan IC LM2596 (buck converter). Dari hasil pengujian terdapat error pada Vout 5 volt dan 12 volt. Namun hal ini masih bisa ditoleransi karena tegangan masih berkisar antara 4.8 volt -5.2 volt.

\section{Pengujian Rangkaian Deret Sensor Gas}

Rangkaian sensor merupakan rangkaian pembagi tegangan sensor MQ-7, TGS 2600, dan MQ-2. Pada pengujian ini tegangan masukan pada rangkaian sensor 5 Volt. Hal yang di 
uji dari Rangkaian sensor adalah Vin, dan tegangan stabil pada sensor.Uji rangkaian deret sensor gas ini masih berkisar di sekitar 5 volt dan masih dalam batas toleransi meskipun ada sedikit error. Error ini tidak berpengaruh pada kinerja dari ketiga sensor tersebut.

\section{Pengujian Deret Sensor Gas}

Pengujian deret sensor gas ini meliputi tiga pengujian, yaitu ketika diberi asap kebakaran hutan, asap rokok, dan asap kendaraan bermotor. Pengujian dilakukan dengan mendekatkan ketiga sensor pada sumber asap. Yang dilihat dari ketiga sensor adalah karakteristik tegangan output yang dihasilkan oleh masing-masing sensor terhadap asap yang dideteksi. Tegangan output bisa ditampilkan setelah adanya pembacaan nilai ADC pada masing-masing sensor.

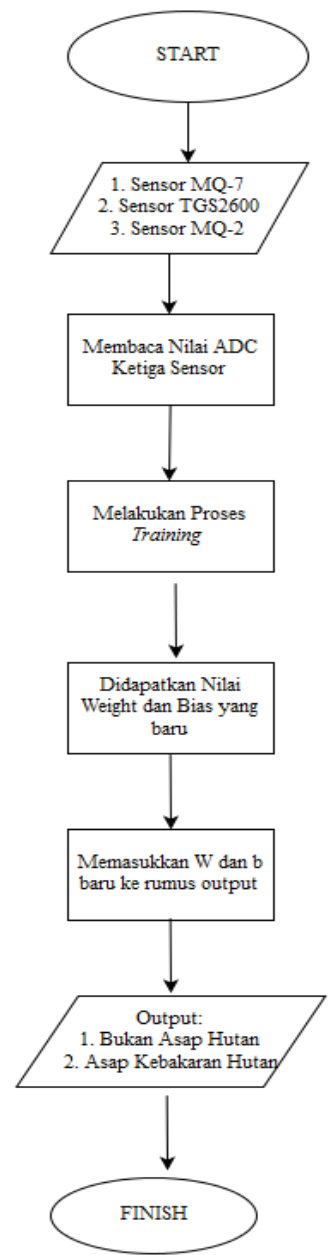

Gambar 9. Flowchart Sistem Jaringan Syaraf Tiruan

Tabel 2.

Hasil Pengujian Deret Sensor Gas Terhadap Asap Hutan

\begin{tabular}{ccc}
\hline $\begin{array}{r}\text { MQ-7 } \\
\text { (volt) }\end{array}$ & TGS 2600 (volt) & $\begin{array}{c}\text { MQ-2 } \\
\text { (volt) }\end{array}$ \\
\hline 0,78 & 1,54 & 1,03 \\
0,84 & 1,69 & 1,18 \\
0,82 & 1,66 & 1,16 \\
0,79 & 1,59 & 1,09 \\
0,77 & 1,55 & 1,07 \\
0,78 & 1,54 & 1,08 \\
0,60 & 1,31 & 0,89 \\
0,59 & 1,35 & 0,95 \\
0,63 & 1,37 & 1,00 \\
\hline \hline
\end{tabular}

Tabel 3.

Hasil Pengujian Deret Sensor Gas Terhadap Asap Rokok

\begin{tabular}{ccc}
\hline \hline $\begin{array}{c}\text { MQ-7 } \\
\text { (volt) }\end{array}$ & TGS 2600 (volt) & $\begin{array}{c}\text { MQ-2 } \\
\text { (volt) }\end{array}$ \\
\hline 0,82 & 1,81 & 1,36 \\
0,79 & 1,78 & 1,33 \\
0,77 & 1,75 & 1,29 \\
0,78 & 1,75 & 1,31 \\
0,78 & 1,75 & 1,30 \\
0,80 & 1,78 & 1,33 \\
0,79 & 1,77 & 1,30 \\
0,76 & 1,74 & 1,25 \\
0,75 & 1,74 & 1.24 \\
\hline \hline
\end{tabular}

Berdasarkan ketiga tabel di atas, dapat dilihat bahwa masingmasing asap memiliki karakteristik tegangan yang stabil sehingga dapat dibedakan masing-masing asap pada sistem jaringan syaraf tiruan.

4. Pengujian Jaringan Syaraf Tiruan

Data dari tabel di atas dimasukkan ke proses trainingJaringan Syaraf Tiruan dan dilakukan perhitungan secara matematis agar bisa dihasilkan nilai $\mathrm{W} 1, \mathrm{~b} 1, \mathrm{~W} 2$, dan $\mathrm{b}$.

Tabel 4.

Hasil Pengujian Deret Sensor Gas Terhadap Asap Kendaraan Bermotor

\begin{tabular}{ccc}
\hline $\begin{array}{r}\text { MQ-7 } \\
\text { (volt) }\end{array}$ & TGS 2600 (volt) & $\begin{array}{c}\text { MQ-2 } \\
\text { (volt) }\end{array}$ \\
\hline 0,39 & 1,40 & 0,78 \\
0,42 & 1,74 & 0,89 \\
0,52 & 1,71 & 0,93 \\
0,51 & 1,78 & 0,90 \\
0,46 & 1,81 & 0,91 \\
0,47 & 1,79 & 0,90 \\
0,48 & 1,72 & 0,96 \\
0,49 & 1,69 & 0,95 \\
0,51 & 1,84 & 0,93 \\
\hline \hline
\end{tabular}

Tabel 5.

Hasil Training untuk Menentukan Bobot $(W)$ dan bias(b)

\begin{tabular}{|c|c|c|c|c|c|c|}
\hline $\begin{array}{l}\text { Peng } \\
\text { ujian }\end{array}$ & & W1 & & b1 & W2 & b2 \\
\hline \multirow{5}{*}{1} & 6,2124 & 0,2202 & 1,0269 & 1,0063 & 3,4922 & \multirow{5}{*}{$-0,7766$} \\
\hline & 4,3092 & 3,2376 & 12,6063 & $-3,4185$ & $-5,1383$ & \\
\hline & $-1,9428$ & $-0,2655$ & 0,9112 & $-0,8459$ & 0,4640 & \\
\hline & 7,3695 & 0,0017 & 1,0983 & 2,7977 & 4,5317 & \\
\hline & $-1,1196$ & 1,2790 & $-0,0398$ & $-0,7513$ & $-0,7731$ & \\
\hline \multirow{5}{*}{2} & 9,4341 & 0,2844 & $-1,5528$ & 4,5844 & 6,7263 & \multirow{5}{*}{0,1873} \\
\hline & 0,8338 & 0,9051 & 3,0477 & $-1,3439$ & $-1,2084$ & \\
\hline & $-4,1231$ & $-1,7904$ & 0,8352 & $-1,2099$ & $-1,8225$ & \\
\hline & 6,0890 & 1,7634 & $-0,7489$ & 2,1679 & 4,3397 & \\
\hline & 0,4496 & 6,6088 & 11,3321 & 3,1740 & $-5,7097$ & \\
\hline \multirow{5}{*}{3} & 2,7683 & $-1,3047$ & $-0,2642$ & $-0,0945$ & 1,7059 & \multirow{5}{*}{$-1,1471$} \\
\hline & 4,4788 & 0,4923 & 0,3310 & $-0,7287$ & 1,8279 & \\
\hline & 8,1210 & $-0,2065$ & 1,9590 & 3,1797 & 5,8401 & \\
\hline & 1,8958 & 0,6337 & $-0,5421$ & $-0,8877$ & 0,6668 & \\
\hline & 0,8868 & 1,9159 & 14,3835 & $-3,6910$ & $-5,3842$ & \\
\hline \multirow{5}{*}{4} & $-1,8652$ & 1,0689 & $-6,3421$ & 0,3344 & 3,2915 & \multirow{5}{*}{$-4,5008$} \\
\hline & 0,0455 & $-1,0576$ & 0,0893 & $-2,2069$ & $-0,2786$ & \\
\hline & $-0,4902$ & $-2,1638$ & 0,1724 & $-2,1951$ & $-1,0138$ & \\
\hline & 1,1491 & $-2,0831$ & 0,4622 & $-2,5536$ & $-0,7053$ & \\
\hline & 12,5148 & $-0,0453$ & $-7,8887$ & 6,3140 & 3,7956 & \\
\hline \multirow{5}{*}{5} & 1,2133 & $-1,1483$ & 0,7151 & $-1,0878$ & 0,7520 & \multirow{5}{*}{4,0913} \\
\hline & 0,3671 & 3,6477 & 15,8003 & $-5,7073$ & $-4,7170$ & \\
\hline & 2,9623 & $-0,6521$ & 0,2429 & $-0,5013$ & 1,8862 & \\
\hline & 5,1940 & $-2,6061$ & $-1,3629$ & 2,3315 & 4,0404 & \\
\hline & $-6,4162$ & $-0,4839$ & $-2,3812$ & $-1,6291$ & $-5,3054$ & \\
\hline \multirow{5}{*}{6} & 0,0781 & $-1,6144$ & 0,6562 & $-1,8369$ & $-1,1176$ & \multirow{5}{*}{$-4,3345$} \\
\hline & 1,6071 & $-2,2803$ & 0,7171 & $-1,6228$ & $-1,0927$ & \\
\hline & 0,5353 & $-0,9903$ & $-0,3337$ & $-1,9438$ & $-0,1586$ & \\
\hline & $-1,2287$ & 1,6299 & $-5,7906$ & $-0,0045$ & 3,0971 & \\
\hline & 13,6120 & $-0,4433$ & $-9,4873$ & 7,1058 & 3,7849 & \\
\hline \multirow{5}{*}{7} & 6,2124 & 0,2202 & 1,0269 & 1,0063 & 3,4922 & \multirow{5}{*}{$-0,7766$} \\
\hline & 4,3092 & 3,2376 & 12,6063 & $-3,4185$ & $-5,1383$ & \\
\hline & $-1,9428$ & $-0,2655$ & 0,9112 & $-0,8459$ & 0,4640 & \\
\hline & 7,3695 & 0,0017 & 1,0983 & 2,7977 & 4,5317 & \\
\hline & $-1,1196$ & 1,2790 & $-0,0398$ & $-0,7513$ & $-0,7731$ & \\
\hline
\end{tabular}


Tabel 6.

Hasil Pengujian Jaringan Syaraf Tiruan

\begin{tabular}{cccc}
\hline \hline Pengujian & $\begin{array}{c}\text { Asap Kebakaran } \\
\text { Hutan }\end{array}$ & Asap Rokok & $\begin{array}{c}\text { Asap Kendaraan } \\
\text { Bermotor }\end{array}$ \\
\hline 1 & Berhasil & Berhasil & Berhasil \\
2 & Berhasil & Berhasil & Berhasil \\
3 & berhasil & Berhasil & Berhasil \\
4 & Berhasil & Berhasil & Berhasil \\
5 & Berhasil & Berhasil & Berhasil \\
6 & Berhasil & Berhasil & Berhasil \\
7 & Berhasil & Berhasil & Berhasil \\
\hline \hline
\end{tabular}

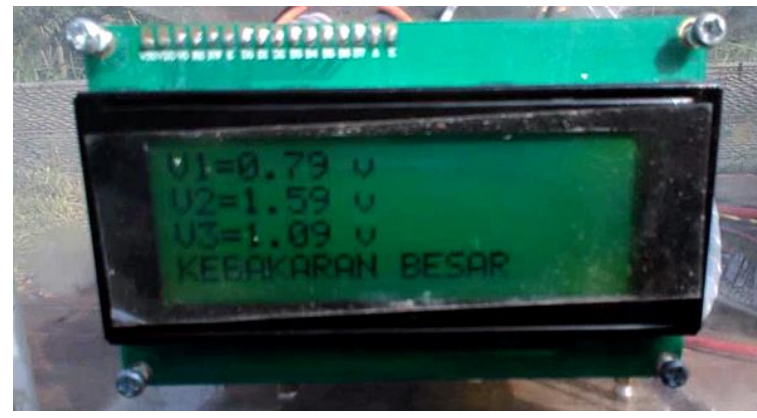

Gambar 10. Hasil Pengujian Sistem Secara Keseluruhan

Dari tabel pengujian di atas dapat disimpulkan bahwa sistem Jaringan Syaraf Tiruan tiga layer dengan fungsi aktivasi sigmoid pada layer tersembunyi dan fungsi aktivasi linear pada layer output ini bisa mendeteksi jenis asap secara baik. Dari 7 kali percobaan yang dilakukan dengan nilai $\mathrm{W} 1, \mathrm{~b} 1, \mathrm{~W} 2$, dan b2 yang berbeda, tidak terdapat error terhadap asap kebakaran hutan, asap rokok, maupun asap kendaraan bermotor.

\section{B. Evaluasi Sistem}

Pengujian sistem secara keseluruhan ketiga sensor gas dapat mendeteksi asap yang diberikan. Pada saat diuji dengan memberikan asap kebakaran hutan, deret sensor gas mengeluarkan tegangan sebesar MQ-7 $=0,79$ volt, TGS 2600= 1,59 volt, dan MQ-2 = 1,09 volt. Setelah beberapa detik melakukan pendeteksian, sistem mendeteksi adanya asap kebakaran hutan dengan skala besar. Hasil ini sesuai dengan apa yang diharapkan dan tidak terjadi error. Namun waktu pendeteksian membutuhkan waktu sekitar 15 detik. Waktu pendeteksian dirasa masih kurang cepat.

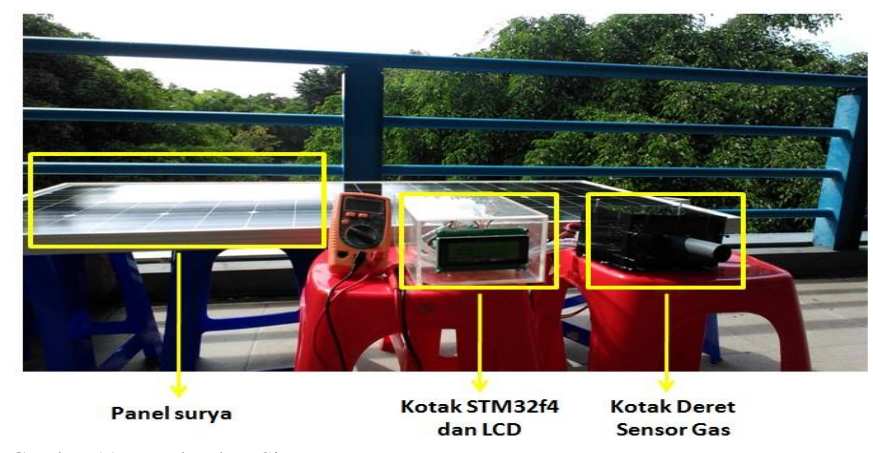

Gambar 11. Keseluruhan Sistem

\section{KESIMPULAN DAN SARAN}

\section{A. Kesimpulan}

Dari perancangan, realisasi, dan pengujian alat pada penelitian ini dapat disimpulkan bahwa deret sensor gas yang terdiri atas MQ-7, sensor TGS2600, dan MQ-2 bisa bekerja dengan baik dengan mendeteksi karakteristik tegangan masingmasing asap. Dari masing-masing karakteristik tegangan tersebut ketika dimasukkan pada sistem Jaringan Syaraf Tiruan kemudian dilakukan percobaan sebanyak 7 kali tidak terdapat error. Evaluasi sistem diberikan sampel berupa asap kebakaran hutan dalam skala besar dan hasil yang diperoleh adalah sistem bisa mendeteksi asap kebakaran hutan dengan waktu pendeteksian sekitar 15 detik.

\section{B. Saran}

Untuk pengembangan alat lebih lanjut hendaknya menambah sensor gas yang lebih banyak supaya data juga lebih akurat. Sistem Jaringan Syaraf Tiruan sebaiknya ditambah lagi neuron dan layer tersembunyi agar keluaran yang dihasilkan paling akurat dan error bisa lebih diminimalisir.

\section{DAFTAR PUSTAKA}

[1] Risnandar, Cecep. 2015. https://jurnalbumi.com/kebakaran-hutan/\#returnnote-227-6 diakses pada tanggal 5 Desember 2015

[2] Sumargo, Wirendro; Nanggara, Soelthon Gussetya; Nainggolan, Frionny A; Apriani Isnenti. 2011. Potret Keadaan Hutan Indonesia Tahun 2000 2009. Forest Watch Indonesia: Jakarta

[3] Panjaitan Berkat, Siringo-Ringo Berliana, dkk. 2013.Sensor Gas. Medan: Technology Science, Sains, fisika

[4] Figaro.2014.Datasheet2600,http://www.figarosensor.com/products/2600. pdf(diakses 23Februari 2015)

[5] Sandoro, Fahmi. 2014. Sensor Gas CO MQ-7. http://jagoanelektronika.com/2014/10/sensor-gas-co-mq-7.html diakses pada tanggal 2 Mei 2016

[6] Hanwei Electronics. 2010. Datasheet MQ-2. http://hwsensor.com /products/mq2.pdf diakses pada tanggal 5 Mei 2016

[7] Setyo Utomo, Hendrik. 2011. Jaringan Syaraf Tiruan. Diktat Kuliah Pengantar Kecerdasan Buatan Universitas Gunadarma: Depok.

[8] STM32F4 Discovery, ST Microelectronics, data sheets, 2012. 